\title{
La obra Sueño en el Pabellón Rojo y su traducción a la lengua española
}

\author{
Patricia AMATE NúÑEZ \\ ibukivskarin@hotmail.com \\ Universidad de Almería
}

Resumen: Sueño en el Pabellón Rojo, uno de los cuatro clásicos de la literatura china, cuenta con traducciones a más de 17 lenguas entre ellas la lengua hispana. En este trabajo se defiende como la biculturalidad del traductor Zhao Zhejiang ha contribuido positivamente a que la traducción al castellano de esta obra culmen de la literatura sea una de las mejores que se encuentran en el mercado. En el estudio se presentan además los elementos lingüísticos más complejos que han intervenido en el proceso de traducción: Chengyu, eufemismos y metáforas. Palabras claves: China, Sueño en el Pabellón Rojo, traducción chino-español, Zhao Zhejiang.

\begin{abstract}
Dream of the Red Chamber, one of the four classics of Chinese literature, which has now been translated into more than 17 languages including the Hispanic language. This approach is based in the assumption of that biculturalism of the translator, Zhao Zhejiang, has contributed positively to the translation into Spanish of this masterpiece as one of the best translated. This paper focused on the linguistic elements which complicating direct translation between Chinese and Spanish language. These are: Chengyu, euphemisms and
\end{abstract}


metaphors. This paper provides concrete examples of the complicate linguistic elements which are found in the novel Dream of the Red Chamber.

Keywords: China, Dream of the Red Chamber, translation between Chinese and Spanish language, Zhao Zhejiang, culture, literature.

\section{Introducción}

Sueño en el Pabellón Rojo (Honglou Meng 红楼梦), también conocido como Historia de una Roca (Shi tou ji 石头记), es una de las cuatro grandes novelas clásicas de la literatura china. Es una obra cumbre que cuenta con su propia disciplina de estudio, la Rojología (Hong Xue 红学). La primera edición de la novela aparece en 1791, cuenta con 120 capítulos y 450 personajes.

En China el estudio de la novela desde su publicación ha estado marcado por las distintas etapas de histórico-políticas del país. El propio Mao en "Carta sobre el problema del estudio del Sueño en el Pabellón Rojo" que escribió el 16 de octubre de 1954 habla sobre las distintas interpretaciones que da lugar la lectura del libro. Entre las interpretaciones más célebres se encuentra la escuela de Ju Shi, letrado de la burguesía china de los años veinte y rojólogo, estudioso de la novela, Ju Shi defendía que la novela trataba sobre la autobiografía amorosa del autor a través de la que dejaba ver su arrepentimiento en asuntos de amor en su juventud, para él la obra describía asuntos femeninos de amistad y sentimientos, en la que se explicaba el amor como algo igual a los sueños y fantasías. Sin embargo, con la fundación de la Nueva China el campo de la Rojología se fue haciendo cada vez más importante y comenzó a refutarse el ideal burgués en el que se fundamenta el libro Estudios sobre "Sueño en el pabellón Rojo" de Yu Ping-po. En la carta de Mao podemos ver como el presidente hace un llamamiento para criticar a la burguesía y a la línea revisionista del Partido es 


\section{P. Amate Núñez}

2019. "La obra Sueño en el Pabellón Rojo y su traducción a la lengua española" Sabir. International Bulletin of Applied Linguistics, 1: 23-37

a partir de entonces, cuando comenzó una lucha revolucionaria contra el idealismo de la escuela de Ju Shi, surgiendo la escuela revisionista que tenía a la cabeza a Chou Yang. Esta escuela estaba caracterizada porque se disfrazada de marxista tomando la teoría de la naturaleza humana de los terratenientes y la burguesía como base teórica y empleando puntos de vista revisionistas para estudiar Sueño en el Pabellón Rojo. Sin embargo y desde un punto de vista más actual existen claras diferencias entre la escuela revisionista y marxista sobre la novela. Para los marxistas Sueño en el Pabellón Rojo es una obra político-histórica que describe el ascenso y la caída de cuatro clanes familiares al final de la sociedad feudal en China dejando atrás la ideología de los rojólogos revisionistas que defendían que la novela trataba del amor romántico. Ya en los años sesenta la escuela de Ju Shi aparece de nuevo ampliando su teoría sobre que la novela es una autobiografía del autor y reforzando la idea de una interpretación político histórico de la historia, teoría que siguen grandes investigadores actuales dedicados a la investigación de la obra.

Es indiscutible desde cualquier punto de vista que entre las páginas de Sueño en el Pabellón Rojo se encuentra información sobre: cultura, educación, clases sociales existentes en la China del siglo XVIII; nobles, gente del pueblo y esclavos. La narración de la obra tras las investigaciones más recientes sobre la vida del autor Cao Xueqing (曹雪芹) (1715-1764) ${ }^{1}$, parece estar claramente influido por sus vivencias, lo que ha marcado uno de los aspectos más importantes de la novela; la forma en la que es reflejada la decadencia de las familias nobles de la época ${ }^{2}$. Los personajes principales en los que está centrada la historia y que son

\footnotetext{
${ }^{1}$ Los 80 primeros capitulo son escritos por Cao Xueqing, los 40 restantes Cheng Weiyuan. ${ }^{2}$ El propio autor de la novela perteneciente a familia noble narra su vida a través de la novela.
} 
reflejo de toda la información expuesta arriba son: Lin Daiyu (林黛玉), Xue Baochai (薛宝钗), y Jia Bauyu (賈寶玉).

Sin embargo, existen otros personajes que merecen especial atención ya que desde mi punto de vista reflejan a la perfección las relaciones sociales de la época en la que se enmarca la novela.

Estos personajes son:

Wang Xifeng (王熙凤), quién es representante dentro de la novela de los valores confucianos otorgados al género masculino. Ella es la encargada de manejar la mansión Rongguo tanto a nivel económico como político, además representa el papel filial de la nuera perfecta.

La Anciana Dama (贾母) abuela del protagonista de la novela Baoyu, ella permite al lector entender cuáles eran los deberes y derechos de la mujer de mayor edad y madre del hijo primogénito en la sociedad Qing.

La anciana Liu (刘姥姥) que permite conocer la diferencia entre las distintas clases sociales y la vida fuera de las ciudades de la época.

Miaoyu (妙玉) que es una muchacha noble que desde su niñez siente devoción por convertirse en monja budista, este personaje acerca al lector a las relaciones religiosas y al poder que representaban para la sociedad.

En definitiva, si hablo de Sueño en el Pabellón Rojo en la actualidad es para mí obligatorio decir que es una enciclopedia de las postrimerías de la cultura china del siglo XVIII, que cubre temas en detalle como: Historia, filosofía, literatura, arquitectura, medicina tradicional china, entre otros muchos. Es una de las obras más importantes a nivel mundial lo que justifica que se convierta en tema de estudio de miles de investigadores.

\section{Traducciones al castellano}


Que la novela sea compleja no ha sido un obstáculo para despertar el interés de investigadores de todo el mundo y que se haya traducida a más de 17 lenguas entre ellas la lengua hispana de la que encontramos dos traducciones completas. La primera, realizada por Mirko Laúer y titulada Sueño de las mansiones rojas y traducida del inglés al castellano. La segunda traducción y de mayor éxito es la realizada Zhao Zhejiang (赵振江) y José Antonio García Sánchez del chino al español y titulada Sueño en el Pabellón Rojo. Este trabajo, como señale en párrafos anteriores, está centrado en la traducción de Zhao Zhejiang.

\section{Biografía de Zhao Zhejiang}

Zhao Zhejiang nació en Beijing en la zona de Shuyin en el año 1940, comenzó sus estudios en la Universidad de Pekín en el año 1959 en el área de filología hispánica, en 1943 se licenció en la facultad de lenguas y literaturas occidentales de la misma Universidad. En la actualidad es catedrático de la Universidad de Pekín y dirige el Centro de Estudios Hispánicos.

Durante los años 1979-1981 vivió en México donde terminó de perfeccionar el español y además publicó sus primeras obras traducidas. En 1987 fue invitado a la Universidad de Granada para traducir el libro Sueño en el Pabellón Rojo ciudad en la que permaneció hasta el año 1989. Gracias a la traducción de esta obra fue premiado con el galardón de la orden Isabel la Católica. En el año 1995 recibió el honor de la Orden Centenario Azul de Rubén Darío y Santiago de Chile, en el año 1999 logró la Orden de Mayo al Mérito en Argentina y en 2004 recibió la Medalla de Honor Presidencial que conmemora el centenario del natalicio de Pablo Neruda.

Zhao Zhejiang además de contar con distinguidos premios también cuenta con una amplia experiencia docente como profesor de español. Desde 1964 hasta 2005 impartió clases de esta lengua en la Universidad de Pekín, de 1998 a 1989 
fue profesor invitado por la Universidad de Granada y realizó junto a José Antonio García Sánchez, en aquel entonces doctorando, la traducción de la novela Sueño en el pabellón Rojo. De 1996 a 1997 volvió a realizar otra estancia en dicha Universidad.

La trayectoria de Zhao Zhejiang como traductor es tan reconocida en China que algunas de sus obras como Historia de la literatura latinoamericana, Introducción de la poesía española e hispanoamericana y Gran jardín de la literatura iberoamericana forman parte de la bibliografía básica en asignaturas del grado en Literatura de la Universidad de Pekín.

Otras traducciones emblemáticas que ha realizado el autor son Introducción de la poesía española e hispanoamericana, Historia de la Literatura Latinoamericana como coautor, Amor, poesía y revolución en Pablo Neruda, además es el traductor e investigador de Rubén Darío, Gabriela Mistral, Pablo Neruda, César Vallejo, Octavio Paz, García Lorca, Juan Ramón Jiménez, Vicente Aleixandre y de Martín Fierro, también ha publicado traducciones como: Antología de la Poesía Hispanoamericana, Antología de la Poesía del Siglo de Oro, Antología de la Poesía Femenina de España (siglo XX), entre otras. El 10 de octubre de 2017 recibió la Mención especial de la Universidad de Granada.

\section{Traducción de la novela}

La historia de la literatura china se distingue principalmente por los siguientes momentos históricos; Poemas Tang, teatro Yuan y novelas Qing categoría en la que entra la obra Sueño en el Pabellón Rojo.

El primer encuentro literario entre China y España se remonta al s.XVI, cuando Juan Cabo tradujo la obra Espejo Rico del claro corazón, Beng Sim Po Cam al español. Posterior a este momento la difusión de la literatura China en España se divide en tres etapas: 
1. Antologías poéticas, libros de filosofía antes 1977-76.

2. Traducciones directas 1975 hasta 2000-2001. Novelas donde entra Sueño en el Pabellón Rojo.

3. Traducciones contemporáneas tras la concesión del nobel a Mao Yan. Min Sun, 2016.

En este trabajo escribo sobre el papel del traductor como mediador cultural lo que me permite defender que la traducción de Zhao Zhejiang y José García Sánchez es una de las mejores que existen sobre Sueño en el Pabellón Rojo gracias a que ambos conocen a la perfección la cultura y lengua hispana. La capacidad que tenga el traductor de traducir la pragmática del texto alejándose de la literalidad léxica que haga perder significado a la obra permite, desde mi punto de vista, hablar de la universalidad de las traducciones literarias. Convierto a través de este punto al traductor en la persona encargada de llevar el campo de lo semiótico de la novela de origen al entendimiento del lector de destino y esto tiene que hacerlo no solo a través de conocer la lengua a la que traduce sino contando con profundo conocimiento de la cultura a la que se dirige. Para esto me apoyo en parte en la opinión de Ortega y Gasset tiene sobre los géneros literarios:

"La traducción no es un doble del texto original; no es, no debe querer ser la obra misma con léxico distinto. Yo diría; la traducción ni siquiera pertenece al mismo género literario que lo traducido. Convendría recalcar esto y afirmar que la traducción es un género literario aparte, distinto de los demás, con sus normas y finalidades propias. Por la sencilla razón de que la traducción no es la obra, sino un camino hacia la obra. Si esta es una obra poética, la traducción no lo es, sino más bien un aparato, un 
artificio técnico que nos acerca a aquella sin pretender jamás repetirla o sustituirla".

J. Ortega y Gasset, 1961, p. 449(apud. Gallego Roca: 1994: 23).

La afirmación de Said sobre que "el orientalismo" es un estilo occidental que pretende dominar la estructura y tener autoridad sobre oriente" (Said, 2005:497) hace que para mí un enfoque desde la comunicación intercultural en la traducción sea imprescindible en este estudio, para que poco a poco se den a conocer nuevas traducciones que permitan desprendernos de ese concepto de "orientalismo" que explica Said. Creyendo firmemente en las palabras de Eugenie Nida: "Para traducir exitosamente, el biculturalismo es aún más importante que el bilingüismo" aprovecho para reforzar la hipótesis desde la que parto en este trabajo; la traducción realizada por Zhao Zhejiang y José Antonio García Sánchez es buena porque ambos son conocedores de la cultura hispana y la lengua castellana como dije en el punto anterior. La importancia del biculturalismo es imprescindible en mi opinión, en especial si hablamos de literatura china ya que se encuentra llena de metáforas, poemas, eufemismos y chengyu ${ }^{3}$ un ejemplo claro de esto es la obra en la que trabajo Sueño en el Pabellón Rojo.

Es por esta causa que el análisis polisistema es para mí de especial interés en la literatura traducida ya que hace hincapié en los ámbitos socioculturales que ayudan al traductor a trabajar de mediador entre culturas y a escoger el método traductológico más acertado para que la recepción del texto sea la correcta por parte de los nuevos lectores. Uno de los ejemplos más célebres realizados en la traducción de la obra Sueño en el Pabellón Rojo ejemplo de lo

\footnotetext{
${ }^{3}$ El chengyu es una frase corta cuyo significado se ha definido a lo largo de la historia de la lengua y representa lo más selecto del idioma y el fruto de la inteligencia del pueblo chino. (Zhang 2004).
} 


\section{P. Amate Núñez}

2019. "La obra Sueño en el Pabellón Rojo y su traducción a la lengua española" Sabir. International Bulletin of Applied Linguistics, 1: 23-37

señalado en las líneas anteriores, fue la traducción que David Hawkes al inglés del título de la novela, en el que en un intento de hacer al lector partícipe del significado del título e intentando acercar al imaginario occidental lo que el color rojo ${ }^{4}$ significa en China, sustituyó dicho color por el dorado. Como indica Huang (2008), esto lo señala Liu Jun, 2004 indicando que "todos los pueblos comparten un mismo concepto, pero usan una expresión distinta para expresarlo". Algo similar dice Walter Benjamín para quien la traducción debe tender a restaurar el lenguaje puro que subyace de todos los idiomas haciendo de la semántica un lenguaje universal en las traducciones en las que el significado está por encima de lo textual.

Ocurre que en ocasiones a la hora de traducir es complicado para los traductores diferenciar imagen cultural de otros recursos retóricos como son los símbolos de la imaginación. Me remito a un ejemplo de la obra seleccionada en concreto con la intención de que lo expuesto quede más claro:

Se nota con facilidad cómo en el lenguaje las alusiones, locuciones, metáforas y proverbios están impregnados de imágenes culturales. A veces, se confunden con otros recursos retóricos, como símbolo, imaginación, metáfora, etc.

Ej. 黛玉一面接了, 抱在怀中, 笑道: “也亏你倒听他的话。我平日和你说的, 全当耳旁风，怎

么他说了你就依，比圣旨还快些！"（《红楼梦》第三回——清]曹雪芹）

Con la estufa en los brazos, Daiyu respondió:

- Así que tú haces lo que ella dice, pero en cambio lo que yo te lo digo te entra por un oído y te sale por el otro. Cumples las órdenes de Zijuan más rápidamente como si se tratara de edictos imperiales. ${ }^{5}$

\footnotetext{
${ }^{4}$ El color rojo connota alegría, felicidad, exquisitez, fiesta, etc. Tsui-Ling, 2008.

${ }^{5}$ El sueño del pabellón rojo, Traducción Zhao Zhejiang y José Antonio García Sánchez, Tomo1, p. 166.
} 
Xiaozhin Jun p. 5:

En el texto la expresión “全当耳旁风" “considerar algo como viento que pasa por los oídos", cuyo sentido implícito es "no hacer caso de un consejo". Analizado desde la perspectiva retórica, esta símil ayuda a crear una figura, y junto con otros elementos de la lengua, la figura adquiere un significado asociativo para convertirse en una imagen.

Otro punto muy importante para los traductores ha sido la complejidad de los términos familiares en chino.

Dice Mikang Zhou, 1995: "China es un país que dan gran importancia al parentesco, dado que es una sociedad colectiva. Debido a esta característica social, existe más vocabulario que en español para expresar las relaciones familiares".

En el caso de la novela que estudio los traductores han solventado este problema a través de notas a pie de página o incluyendo términos genéricos que si existen en nuestra cultura hispana.

Un ejemplo concreto lo encontramos en el capítulo 3 de la novela p. 63 en el que se hace referencia a la abuela materna de Daiyu, suegra de Yucun, la Anciana Dama, en la traducción española se utiliza la palabra genérica suegra mientras que en la versión china ${ }^{6}$ aparece 外母 (外 fuera) (母 madre) 外 es el caracter que hace diferencia con familiares paternos que se consideran directos y no foráneos.

A través de estos ejemplos es sencillo entender lo que Miguel Gallego Roca, 1994 nos dice sobre la literatura presentada como un hecho social en el que sin duda la obra Sueño en el Pabellón Rojo es un gran ejemplo de las relaciones que se establecen entre texto y sociedad, tanto en la producción de aquel como en su recepción, consideradas ambas como acciones sociales

\footnotetext{
6 红楼梦 edición Beijing Normal University Publishing Group. Tomo I, p. 45 capítulo 3.
} 
fundamentadas sobre ciertos motivos y orientadas a unos fines determinados, motivos y fines especifico de una época o un grupo social. La socialización de los individuos a través de un sistema de normas y valores que desarrolla una serie de aparatos ideológicos entre los cuales el más relevante es el aparato del aprendizaje en las escuelas, algo que se muestra perfectamente en la novela. La literatura en tanto que institución, posee una organización autónoma, funciona como sistema socializador, y desempeña los roles de un aparato ideológico. En la introducción del trabajo hacía un pequeño resumen sobre el fuerte valor ideológico que Sueño en el Pabellón Rojo tiene en China.

De los elementos más complicados traducidos en la novela se sitúa el eufemismo, la distancia cultural entre China y España hace que la traducción de este elemento sea de un nivel complejo. Los eufemismos aparecen en cinco grandes grupos- muerte- sexualidad- enfermedad- y las funciones corporales.

Por ejemplo, si nos centramos en los cinco campos en los referentes culturales: ecología, cultura material, cultura social, cultura religiosa y cultura lingüística. Sueño en el Pabellón Rojo aparecen todos ellos.

A la hora de traducir siempre es importante tener en cuenta la carga del eufemismo ya que de ella va a depender la elección del tipo de traducción. Las dos técnicas más usadas en la novela han sido la traducción literal y la explicación seguida de cerca por el equivalente eufemístico.

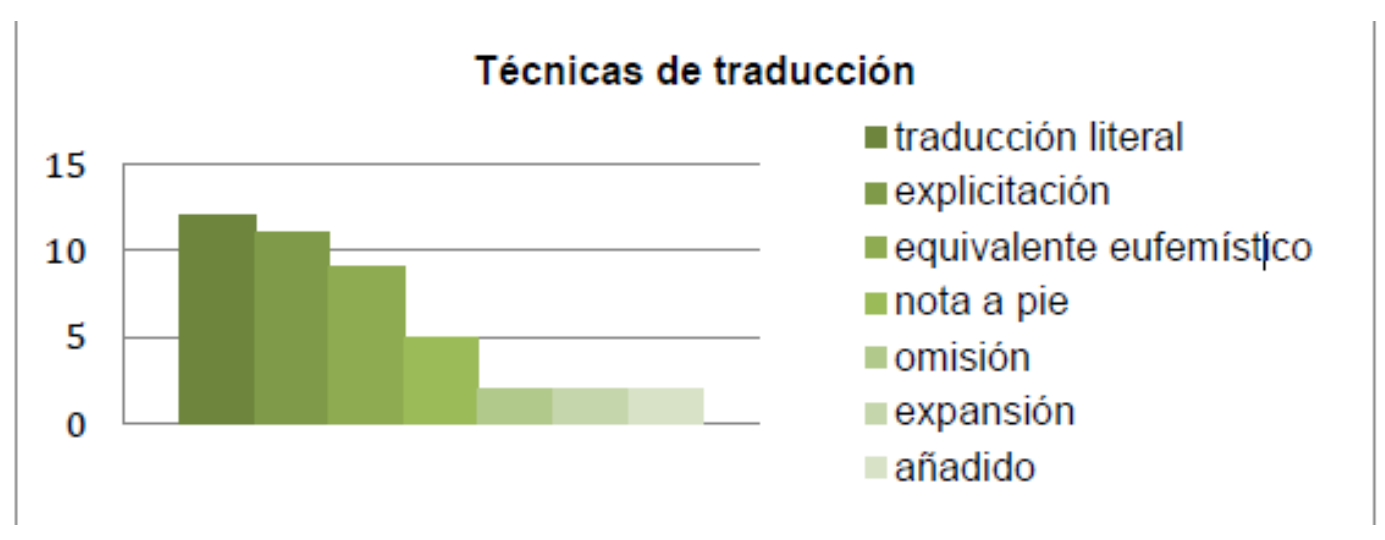

Fuente: Cai 2015 
Otra constante complejidad en la traducción de Sueño en el Pabellón Rojo ha sido la metáfora. Encontramos de tipo conceptual, temático, metáfora en nombre de personajes, metáfora orientacional y metáforas muertas.

Una de las metáforas que aparecen en la novela que ha despertado mayor interés de estudio ha sido "El ser humano es una planta" considerada como metáfora conceptual ${ }^{7}$ de tipo estructural, la expongo como ejemplo en este trabajo para ver cómo de complejo es el estudio sobre la traducción de esta obra.

Según Ying Luo, 2018 explica el afanoso trabajo que han hecho los traductores para que el público receptor sea capaz de entender tan compleja metáfora; Naturaleza, en chino Ziran自然 o en un sentido más confuciano Tian 天, este concepto puede ser entendido a través de las constantes referencias que se hacen en la novela de forma distinta lo que ocasiona que se produzcan lo que es conocido como "naturaleza parcial de la estructuración metafórica" según la cual "solo se proyecta información coherente con la estructura imagen-esquemática del dominio meta" Ying Luo, 2018.

Este estudio realizado por Ying Luo, 2018 refuerza la elección de la versión de Zhao como traducción ejemplar de la novela cuando dice que: "Entre los datos en que se excluye la imagen planta de ambas traducciones se nota una mayor precisión del uso léxico en la versión de Zhao y García Sánchez ${ }^{8}$

\footnotetext{
${ }^{7}$ Metáfora entendida desde una perspectiva teórica refleja la forma de pensar y los razonamientos de los hablantes de una determinada comunidad.

${ }^{8}$ Para los ejemplos citados por Ying Luo acudir a la p. 22 del artículo "La metáfora "El ser humano es una planta" en Sueño en el Pabellón Rojo (红楼梦) y su traducción al español: un análisis desde la perspectiva cognitiva".
} 


\section{Conclusión}

Sueño en el Pabellón Rojo es una obra cumbre de la literatura china pero también de la literatura de todas partes del mundo. La traducción de Zhao Zhejiang es sin duda una de las grandes traducciones que se han realizado sobre la obra, la experiencia del traductor junto al conocimiento de la lengua y cultura hispana han conseguido que el público pueda leer esta obra maestra sin perder detalle y conociendo los entresijos de la cultura Qing en toda su amplitud. Zhao Zhejiang ha sabido solventar con grandeza todos los problemas que traductores que comienzan a trabajar con novelas chinas se encuentran al comenzar su trabajo; Chengyu, metáfora, eufemismo como los más destacados y que han sido expuestos en este trabajo.

En resumen, Sueño en el Pabellón Rojo ya sea en su versión china o en sus versiones traducidas me atrevo a decir que es seguirá siendo objeto de investigaciones, pues se trata sin duda y remitiéndome al inicio del trabajo de una enciclopedia de la cultura china.

\section{Bibliografía}

Borges, J. L.

1998. Textos cautivos. Madrid: Alianza.

Cai, Y.

2015. "La Traducción Del Eufemismo Del chino al español: Hongloumeng y su traducción sueño en el Pabellón Rojo" en Hikma 14: 37.

Gallego Roca, M.

1994. Traducción y literatura: los estudios literarios ante las obras traducidas. Madrid: Jucar.

Hurtado Albir, A. 
2001. Traducción y traductología. Introducción a la traductología. Madrid: Cátedra. Janés, C.

2005. Guardar la casa y cerrar la boca. En torno a la mujer y la literatura. Madrid: Siruela.

$\mathrm{Ke}, \mathrm{W}$.

1995. "Translation and Culture: With Special Reference to the Translation of Hong Lou Meng" en Babe/41 (1): 24-35.

$\mathrm{Ku}$, Meng Hsuan. La traducción de los elementos lingüísticos culturales

(chino-español). Estudio de "Sueño en las estancias rojas". Dirección: Dra. Amparo Hurtado y Dra. Lucía Molina. Barcelona: Universitat Autónoma de Barcelona, 2006. Shep, Sydney

Mikang, Z.

1995. "Mikang, Zhou. estudio comparativo del chino y el español aspectos lingüísticos y culturales." Barcelona: Universidad Autónoma de Barcelona. Min, S.

2018. "Las literaturas china y española frente a frente" en Actas del IX Congreso de Hispanistas de Asia. Taiwan: Monográficos Sinoele, 824-1099

Nida, E.

1945. "Linguistics and ethnology in translation problems" en Word, 1:2, 194-208, Paz, O.

1971. Traducción: literatura y literalidad. Barcelona: Tusquets.

Reiss, K. y H. Vermeer.

1996. Fundamentos para una teoría funcional de la traducción. Madrid: Akal.

Said, E. W,

1978. El Orientalismo. Madrid: Debate, 2005.

Tsui-Ling, $\mathrm{H}$.

2008. "La traducción del sentido cultural implícito: análisis de las diferencias entre la cultura occidental y la china" en Pegenaute, L.; Decesaris, J.; Tricás, M. 
y E. Bernal [eds.] Actas del III Congreso Internacional de la Asociación Ibérica de Estudios de Traducción e Interpretación. La traducción del futuro: mediación lingüística y cultural en el siglo XXI. Barcelona: PPU. Vol. 1: 101-114.

Xiaojin, Z.

2018. "Reflexiones sobre la imagen cultural china y su traducción intercultural: un enfoque de Bassnett" en Actas del IX Congreso de Hispanistas de Asia. Taiwan: Monográficos sinoele, 824-1099

Xueqin, $C$.

1791. Sueño en el Pabellón Rojo (Memorias de una roca). Traducción de Zhao Zhenjiang y de José Antonio García Sánchez. Edición revisada por Alicia Relinque Eleta. Madrid/Granada: Galaxia Gutenberg-Universidad de Granada, 2010.

罗莹, Ying L.

2018. "La Metáfora EL SER HUMANO ES UNA PLANTA En Sueño en el Pabellón Rojo (红楼梦) y su traducción al español: un análisis desde la perspectiva cognitiva" en Círculo De Lingüística Aplicada A La Comunicación 74: 5254.

Zhang, Y.

2004. "Cultural Comparison and Translaltion" en Journal of Shandong Institute of Commerce and Technology 4 (1): 52-54. 